\title{
Differences Between African Americans and Whites in Their Perceptions of Alzheimer Disease
}

\author{
*J. Scott Roberts, †Cathleen M. Connell, *Dawn Cisewski, $\ddagger$ Yvonne G. Hipps, \\ $\S$ Serkalem Demissie, and $* \|_{\text {Robert C. Green }}$ \\ From the Departments of *Neurology and ${ }^{*}$ Medicine (Genetics Program), Boston University School of Medicine, and the \\ $\S$ Department of Biostatistics, Boston University School of Public Health, Boston, Massachusetts; the †Department of Health \\ Behavior and Health Education, University of Michigan School of Public Health, Ann Arbor, Michigan; and the $\ddagger$ Department of \\ Pharmacology, Morehouse School of Medicine, Atlanta, Georgia, U.S.A.
}

\begin{abstract}
Summary: To design optimal health services and education programs for Alzheimer disease (AD), it is important to understand cultural differences in perceptions of the disorder. In this study, we investigated differences between African Americans and whites in their beliefs, knowledge, and information sources regarding AD. We distributed a written questionnaire through lay and professional organizations and meetings in the southeastern United States, yielding a sample of 452 adults (61\% white, 39\% African American; 78\% female; mean age 47 years; $33 \%$ with family history of AD). The questionnaire assessed the following: (1) illness beliefs, (2) factual knowledge, (3) sources of information, and (4) perceived subjective threat of AD. African Americans and whites were generally similar in their beliefs about common symptoms, prominent risk factors, and the effectiveness of treatments for AD (although whites expressed greater certainty in these beliefs than African Americans). In comparison to whites, African Americans showed less awareness of facts about AD, reported fewer sources of information, and indicated less perceived threat of the disorder. These preliminary findings suggest important distinctions between African Americans and whites in their knowledge about, and conceptualization of, AD. Follow-up studies with more representative samples and more fully validated measures will be necessary to confirm these differences. Health psychologic research suggests that such differences in illness perceptions could shape response to disease burden, assessment and diagnosis, and available health care options. Key Words: Alzheimer diseaseKnowledge-Beliefs-African American.
\end{abstract}

Alzheimer disease (AD) has been described as a "silent epidemic" among African Americans (Alzheimer's Association, 2002), and epidemiologic research suggests that the disorder may disproportionately affect this population (Froehlich et al., 2001; Green et al., 2002). However, African Americans are underserved with regard to

Received June 13, 2002. Accepted September 12, 2002.

Supported by National Institutes of Health grants HG/AG02213 (REVEAL Study), AG13846 (Boston University Alzheimer's Disease Center), and AG09029 (MIRAGE Study).

Address correspondence and reprint requests to Dr. J. Scott Roberts, Boston University Alzheimer's Disease Center, 715 Albany Street, E-842 Boston, Massachusetts 02118, U.S.A.; e-mail: jscottr@bu.edu dementia care, often receiving services later in the disease course than whites, or not at all (Manly et al., 1999). To address these health disparities, the design of culturally informed interventions and related health services will be important (Gallagher-Thompson et al., 2000). To inform such efforts, we need a better understanding of differences between African Americans and whites in how they conceptualize and learn about AD.

Although a few studies have examined how African Americans perceive disorders such as breast cancer and hypertension (Michielutte and Diseker, 1982; Kumanyika et al., 1989; Barroso et al., 2000), little such research has focused on AD. Anecdotal evidence suggests 
that, when compared with whites, African Americans are more likely to view significant memory loss in old age as an expected part of the aging process (as opposed to a sign of disease) and to show greater reluctance in placing a memory-impaired loved one in a nursing home (Hargrave, 2001). Research on caregiving for $\mathrm{AD}$ has also found that, when compared with their white counterparts, African American caregivers are less likely to perceive patient-related problems as burdensome or to view caregiving as a disruptive experience (Haley et al., 1996; Connell and Gibson, 1997; Janevic and Connell, 2001). Despite these important findings, to our knowledge, there have been no systematic cross-cultural examinations of those illness perceptions that would be likely to influence health behaviors and decision-making with regard to $\mathrm{AD}$. According to one prominent model of health stress and coping (Leventhal et al., 1997), perceptions of disorder symptoms, causes, and controllability are key aspects of illness representations: schemas that organize and shape response to medical difficulties. Other theories of health behavior have focused on the importance of perceived threat in determining reaction to health problems (Becker, 1974; Lazarus and Folkman, 1984). Guided by such models, we examined differences between African Americans and whites in terms of the following perceptions of $\mathrm{AD}$ : (1) illness beliefs, (2) factual knowledge, (3) sources of information, and (4) perceived threat of the disorder.

\section{METHODS}

\section{Procedure}

The survey used in this study has been described in a previous publication (Green at el., 1997). Briefly, survey development included in-depth interviews and a series of focus groups with a culturally diverse sample of approximately 70 adults from the Atlanta, Georgia area. The final survey consisted of a total of 82 questions assessing attitudes, beliefs, and knowledge regarding $\mathrm{AD}$ and health care options for the disorder. The survey was distributed to distinct populations of volunteers to achieve a convenience sample with cultural and socioeconomic diversity. The volunteers included participants in caregiver and gerontology conferences, support groups, and health fairs held in Alabama, Georgia, and Florida; also recruited were members of church congregations and civic organizations in the Atlanta metropolitan area. A total of 452 white and African American respondents completed the survey.

Although this was clearly a nonrepresentative sample, efforts were made to ensure diversity with regard to family history of $\mathrm{AD}$ and racial/ethnic background. African
Americans have generally been underrepresented in research on $\mathrm{AD}$, in part due to expenses, transportation difficulties, and lack of rapport with clinic staff (Ballard et al., 1993; Connell et al., 2001). We made special efforts to overcome these barriers, using principles recommended for recruitment of minority participants in dementia research, such as the use of African American recruiters and coordinators and collaboration with African American church and community leaders (Gauthier and Clarke, 1999).

\section{Measures}

The primary focus of the survey was to address perceptions of AD. Guided both by health psychologic theory and our own previous research (Roberts, 2000; Roberts and Connell, 2000), we organized survey items into four specific domains reflecting: (1) illness beliefs, including those about characteristic symptoms, potential risk factors, and possible treatments for AD, (2) knowledge of well-established facts about AD, (3) sources of information about the disorder, and (4) perceived threat of $\mathrm{AD}$ to the individual respondent.

\section{Illness Beliefs}

This domain consisted of three sections: (1) symptom beliefs, (2) risk factor beliefs, and (3) treatment beliefs. Participants responded to items using a yes/no/don't know response format. For symptom beliefs, participants responded to a list of seven symptoms and indicated whether these commonly occur in AD. Items included symptoms characteristic of AD (e.g., memory loss, sleep disruption) and one that is not (jerkiness in arms and legs). For risk factor beliefs, participants responded to a list of 10 items and indicated whether they believed them to be authentic risk factors for AD. Items included biologic (e.g., genetics) and environmental (e.g., head injury) risk factors as well as other variables that are associated with $\mathrm{AD}$ (e.g., older age). Other items were included that are not known to be risk factors for $\mathrm{AD}$ (e.g., viral infection).

For treatment beliefs, participants responded to 27 questions asking about the perceived effectiveness of various means of treating or reducing risk for $\mathrm{AD}$. Items included both treatments that have been shown to be effective for $\mathrm{AD}$ and those that have not. Six questions addressed potential treatments for behavioral and agitation (e.g., increased supervision), seven questions addressed potential treatments for memory problems associated with $\mathrm{AD}$ (e.g., Aricept), seven questions addressed potential treatments for slowing the progression of $\mathrm{AD}$ (e.g., anti-inflammatory medications), and seven ques- 
tions addressed potential treatments for reducing one's risk of developing $\mathrm{AD}$ (e.g., estrogen). Treatments included both behavioral (e.g., physical exercise) and medical (e.g., medications) interventions. In addition, participants were asked whether there is a blood test that can diagnose AD. Participants also indicated beliefs that a cure for $\mathrm{AD}$ would be found either within the next 5 years or within their lifetime, and whether nursing home placement is eventually needed for almost all patients with AD (5-point Likert scale: $1=$ strongly agree, $5=$ strongly disagree).

\section{Factual Knowledge}

Following consultation with a multidisciplinary panel of experts at the Boston University Alzheimer's Disease Center, we determined that a subset of the illness belief items were sufficiently well established by scientific research as "facts" so that they could be included in a scale assessing objective knowledge about AD. We chose 13 such items from the domains of symptom beliefs, risk factor beliefs, and treatment beliefs [e.g., memory loss is a symptom of $\mathrm{AD}$ (yes); older age is a risk factor for $\mathrm{AD}$ (yes); there is a blood test that can diagnose AD (no)]. The primary scale score represented the total of number of items answered correctly (range 0-13). Subscale scores were also generated for numbers of items answered "wrong" (i.e., the incorrect yes/no response was given) and for numbers of items answered "don't know" or left blank. Participants were not specifically informed that "don't know" or blank responses would be counted as incorrect.

\section{Sources of Information}

Participants were asked to indicate whether they had learned about $\mathrm{AD}$ from one or more of eight potential sources of information (e.g., physicians, relatives, the media). Responses to these questions were summed to yield an overall score indicating how many of the information sources participants endorsed (range 0-8). The reliability coefficient for this scale was 0.71 .

\section{Perceived Threat of $A D$}

Finally, we created a scale of seven items that measured concern or worry about AD (e.g., "I am worried that I will develop AD," "The thought of developing AD scares me"). Each item was measured on a 5-point Likert scale: $1=$ strongly agree to $5=$ strongly disagree. The reliability coefficient for this scale was 0.83 . In addition, we asked participants to indicate their belief that $\mathrm{AD}$ is "just part of growing older": $1=$ strongly agree to $5=$ strongly disagree.

\section{Data Analysis}

Descriptive statistics were used to summarize sample demographics and to compare the two racial groups on responses on individual survey items. Differences between African American and whites on categorical outcomes of interest were examined using chi-square analyses. Cronbach's alpha was used to assess the reliability of the sources of information and perceived threat of $\mathrm{AD}$ scales.

Differences between African American and whites on continuous outcomes of interest were initially examined through analyses of variance. Next, analyses of covariance were conducted to control for the following covariates: age, gender, education [four categories: (1) high school or less, (2) some college or 2-year degree, (3) college graduate, (4) graduate or professional school], income (below $\$ 40,000$ versus $\$ 40,000$ and above), family history (yes/no), and caregiving history (yes/no). Given differences between African Americans and whites on the potentially confounding variables of education and income, we also examined racial group differences on our outcomes of interest within two subsamples matched by socioeconomic status (SES). The "low SES" subsample included participants who had not graduated college and whose income was $<\$ 40,000$; the "high SES" subsample included participants who had graduated college and whose income was $\geq \$ 40,000$.

\section{RESULTS}

\section{Demographics}

Of the 452 respondents, $61 \%(n=278)$ were white and $39 \%(n=174)$ were African American. The sample had a mean age of 47 years $(\mathrm{SD}=14$ years; range $22-90$ years) and was $78 \%$ female. Median education level was college graduate, and median income range was $\$ 40,000-\$ 59,999$. A total of $33 \%$ of participants reported a family history of $\mathrm{AD}$, and $20 \%$ reported a caregiving history. Table 1 shows demographic characteristics by racial group. On average, whites were older and reported higher levels of education (median education level (white) $=$ college graduate versus median education level (African American) = some college or 2-year degree) and income (median income range (white) = $\$ 40,000-\$ 59,999$ versus median income range (African American) $=\$ 20,000-\$ 39,999)$. No significant racial group differences were found with regard to gender, family history of $\mathrm{AD}$, or caregiving history.

\section{Illness Beliefs}

African Americans and whites were similar with regard to numerous beliefs about AD. For example, both 
TABLE 1. Sample demographics $(\mathrm{N}=452)$

\begin{tabular}{lcc}
\hline & African & \\
Demographic characteristic & American & White \\
\hline Mean age* (years, SD) & $43.9(13.5)$ & $48.5(14.5)$ \\
Sex $\%$ female) & 75 & 80 \\
Education* $\%)$ & & \\
$\quad$ High school graduate or less & 19 & 13 \\
$\quad$ Some college or 2-year degree & 33 & 24 \\
$\quad$ College graduate & 15 & 21 \\
$\quad$ Graduate or professional school & 33 & 42 \\
Income* $\%$ ) & 23 & 12 \\
$\quad$ \$20,000 & 36 & 29 \\
$\quad \$ 20,000-\$ 39,999$ & 18 & 21 \\
$\quad \$ 40,000-\$ 59,999$ & 10 & 21 \\
$\quad \$ 60,000-\$ 79,999$ & 13 & 17 \\
$\geq \$ 80,000$ & & 35 \\
Family history of Alzheimer's disease & 29 & 23 \\
$\quad \%$ yes) & 16 & \\
Caregiving history (\% yes) &
\end{tabular}
$0.05)$.

groups most commonly endorsed memory loss, agitation, and sleep disruption as symptoms; both viewed genetics and older age as the most important risk factors; and both endorsed "behavioral" interventions such as mental stimulation, physical exercise, and taking vitamins as the most effective treatments (e.g., mental stimulation was seen as the most effective treatment in each of the three domains it was offered as an option).

However, the two groups differed with regard to the certainty of their illness beliefs. On 44 of 45 items, African Americans endorsed the "don't know" option in proportionally greater numbers than whites. The two groups also differed with regard to specific treatment beliefs. For example, African Americans endorsed more strongly than whites the belief that a cure for AD would be found in the next 5 years [adjusted mean (white) = 3.4 vs. adjusted mean (African American) $=2.9, p<$ 0.001 ), whereas whites expressed more strongly the belief that nursing home placement would eventually be needed for almost all patients with AD (adjusted mean $($ white $)=2.2$ vs. adjusted mean (African American) $=$ 2.6, $p<0.05)$.

\section{Factual Knowledge}

Whites answered $60 \%$ of items correctly on the 13item knowledge scale, compared with $42.5 \%$ for African Americans. On average, whites gave wrong answers to $13.5 \%$ of items compared with $14 \%$ for African Americans. Finally, whites responded "don't know" to or left blank $26.5 \%$ of items compared with $43.5 \%$ of African Americans (the vast majority of these responses were "don't know," as only $4.2 \%$ of all responses were left blank). The most commonly missed items among all respondents were as follows: (1) medications are available to reduce the risk of developing $\mathrm{AD}$ (no; $77 \%$ incorrect); (2) Aricept and Tacrine can treat the memory symptoms of $\mathrm{AD}$ (yes; $69 \%$ incorrect); and (3) exposure to aluminum is a significant risk factor for AD (no; $65 \%$ incorrect). Table 2 presents responses on each of the scale items by racial group.

\section{Sources of Information}

Whites endorsed an average of 4.6 information sources on the 8-item scale, whereas African Americans endorsed an average of 3.1 information sources. The

TABLE 2. Responses on factual knowledge scale, by racial group

\begin{tabular}{|c|c|c|c|c|c|c|}
\hline & \multicolumn{3}{|c|}{ African American } & \multicolumn{3}{|c|}{ White } \\
\hline & $\%$ yes & $\%$ no & $\%$ don't know & $\%$ yes & $\%$ no & $\%$ don't know \\
\hline \multicolumn{7}{|l|}{ Symptoms } \\
\hline Loss of memory & $92 *$ & 2 & 6 & $99 *$ & 0 & 1 \\
\hline Agitation & $69 *$ & 6 & 25 & $90 *$ & 4 & 6 \\
\hline Sleep disruption & $65^{*}$ & 7 & 28 & $84 *$ & 3 & 13 \\
\hline Jerky movements of arms and legs & 23 & $42 *$ & 35 & 28 & $52 *$ & 20 \\
\hline \multicolumn{7}{|l|}{ Risk factors } \\
\hline Genetics & $70 *$ & 5 & 25 & $91 *$ & 1 & 8 \\
\hline Older age & $65^{*}$ & 13 & 22 & $70 *$ & 16 & 13 \\
\hline Viral infection & 13 & $27 *$ & 60 & 14 & $42 *$ & 43 \\
\hline Exposure to aluminum & 17 & $23 *$ & 60 & 19 & $42 *$ & 39 \\
\hline \multicolumn{7}{|l|}{ Diagnosis and treatment options } \\
\hline Tranquilizers for agitation & $32 *$ & 18 & 50 & $43^{*}$ & 31 & 27 \\
\hline More supervision for behavior problems & $52 *$ & 14 & 33 & $57 *$ & 22 & 21 \\
\hline Tacrine/Aricept for memory problems & $18^{*}$ & 8 & 74 & $39 *$ & 10 & 51 \\
\hline Medications to reduce risk of $\mathrm{AD}$ & 41 & $14 *$ & 45 & 24 & $29 *$ & 47 \\
\hline Blood test to diagnose disease & 27 & $22 *$ & 51 & 10 & $59 *$ & 31 \\
\hline
\end{tabular}

*Percent of respondents endorsing correct response. 
most commonly endorsed information sources among all respondents were as follows: (1) my own readings (83\%), (2) the media (80\%), and (3) nonphysician health care professionals (78\%). Table 3 presents responses on each of the scale items by racial group.

\section{Perceived Threat of AD}

Table 4 presents responses on each of the scale items by racial group. In addition, African Americans were more likely than whites to express the belief that $\mathrm{AD}$ is "just part of growing older" [26\% (African American) vs. $12 \%$ (white), $p<0.001]$.

\section{Multivariate Analyses}

Analyses of covariance adjusting for age, gender, education, income, family history, and caregiving history found significant differences between African Americans and whites on the factual knowledge, sources of information, and perceived threat of AD scales. Post hoc analyses of means showed that when compared with African Americans, whites endorsed more knowledge items correctly [adjusted mean (white) $=7.6$ vs. adjusted mean $($ African American $)=5.6, p<0.001]$, reported a greater number of information sources about AD [adjusted mean (white) $=4.7$ vs. adjusted mean (African American $)=3.5, p<0.001]$, and perceived $\mathrm{AD}$ as a greater threat [adjusted mean (white) $=19.5$ vs. adjusted mean $($ African American $)=23.1, p<0.001]$. Table 5 summarizes findings from the analyses of covariance. Supplementary analyses testing for interaction effects between race and covariates found interaction effects for race and age with regard to sources of information and perceived threat of $\mathrm{AD}$.

\section{Post Hoc Analyses Among Subsamples Matched by Socioeconomic Status}

Analyses of variance assessed racial group differences in both a "low SES" (education < college graduate, in-

TABLE 3. Responses on sources of information scale, by racial group

\begin{tabular}{lcc}
\hline & \multicolumn{2}{c}{$\%$ endorsing } \\
\cline { 2 - 3 } Source of information & African American & White \\
\hline Own readings & 76 & 93 \\
Media & 54 & 83 \\
Other health care professionals & 44 & 80 \\
Received information & 49 & 77 \\
Friends & 41 & 62 \\
Physicians & 17 & 52 \\
Lay organizations & 32 & 52 \\
Relatives & & 33 \\
\hline
\end{tabular}

come $<\$ 40,000)$ and "high SES" subsample (education $\geq$ college graduate, income $\geq \$ 40,000$ ). The "low SES" subsample included 124 participants (68 African Americans, 56 whites). The "high SES" subsample included 169 participants (116 whites, 53 African Americans). In both subsamples, whites endorsed more knowledge items correctly [low SES sample: mean (white) $=6.3$ vs. mean (African American) $=4.5, p<0.001$; high SES sample: mean (white) $=8.5$ vs. mean (African American) $=7.2, p<0.01]$. In both subsamples, whites reported a greater number of information sources about AD [low SES sample: mean (white) $=4.1$ vs. mean $($ African American $)=2.4, p<0.001$; high SES sample: mean $($ white $)=4.7$ vs. mean $($ African American $)=3.7$, $p<0.01]$. Finally, in both subsamples whites perceived $\mathrm{AD}$ as a greater threat [low SES sample: mean (white) $=$ 22.3 vs. mean (African American) $=25.1, p<0.05$; high SES sample: mean (white) $=20.6$ vs. mean (African American $)=24.2, p<0.001]$.

\section{DISCUSSION}

This is the first study to examine differences between African Americans and whites across a wide range of important perceptions of Alzheimer disease. Although the findings here will need to be replicated with a more representative sample and more fully validated measures, they suggest notable differences between the two groups in their views of AD. Strikingly, we found race to be a more powerful variable than even family or caregiving history in explaining differences in illness perceptions. Racial group differences on outcomes of interest were consistent even when examined within subsamples matched by socioeconomic status. African Americans in this study perceived $\mathrm{AD}$ as a lesser subjective threat than did whites, noting a lower level of concern about developing the disorder and less worry about its possible consequences. African Americans showed less awareness of established facts regarding the disorder (although they were also more willing to acknowledge their lack of knowledge), and they also reported a fewer number of sources of information about AD. Racial group differences in sources of information and perceived threat were most pronounced in younger age groups (i.e., $<60$ years). Although both groups were generally in agreement as to the salient symptoms, risk factors, and treatments for $\mathrm{AD}$ (noting greater belief in the efficacy of behavioral treatments vis-a-vis medical interventions), African Americans held less certain views on these topics than their white counterparts. Finally, African Americans believed less strongly than whites in the need for eventual nursing home placement of patients with AD.

Our findings suggesting that African Americans have 
TABLE 4. Responses on perceived threat of Alzheimer disease (AD) scale, by racial group

\begin{tabular}{lcc}
\hline & \multicolumn{1}{c}{$\begin{array}{c}\% \text { agreeing } \\
\text { (median response) }\end{array}$} \\
\cline { 2 - 3 } Scale items & African American & White \\
\hline The thought of developing AD scares me. & 45 (undecided) & 74 (agree) \\
AD is one of the worst diseases I can think of. & 39 (undecided) & 74 (agree) \\
I would like to know if I am going to develop AD. & 43 (undecided) & 53 (agree) \\
I am worried I will develop AD. & 26 (disagree) & 41 (undecided) \\
I occasionally think I will develop AD. & 26 (disagree) & 40 (undecided) \\
I believe that I will someday develop AD. & 15 (disagree) & 21 (undecided) \\
I think about developing AD at least once a week. & 6 (disagree) & 11 (disagree) \\
\hline
\end{tabular}

lower levels of factual knowledge about and fewer information sources for $\mathrm{AD}$ are consistent with similar research on other medical disorders. For example, studies in the cancer and hypertension literature have found that African Americans had less knowledge than whites about risk factors, symptoms, causes, detection, and treatment (Michielutte and Diseker, 1982; Kumanyika et al., 1989). For many reasons (e.g., economic barriers, institutional racism, mistrust of the medical system), African Americans have been less likely to use geriatric services and to participate in research on Alzheimer disease (Welsh et al., 1994; Connell et al., 2001). They may have less access to the health care system for AD and, as a result, less formal knowledge about the disorder. Indeed, African Americans in this sample were less likely than whites to report that they had learned about AD from physicians and other health care professionals.

Even though they are not at greater objective risk for $\mathrm{AD}$, white respondents showed more concern about de- veloping $\mathrm{AD}$ than their African American counterparts. Although other factors are clearly involved, this heightened sense of concern about AD may help account for the fact that white patients with dementia present for medical care earlier in the disease course than their African American counterparts (Manly et al., 1999). Our results in this area also seem consistent with previous findings that $\mathrm{AD}$ poses a greater subjective burden to white caregivers (Lawton et al., 1992). It has been suggested that dementia may be a less negative diagnosis for African Americans than whites for several reasons: specifically, African Americans' greater access to extended church and family support networks, experience adapting to adversity, greater reliance on positive coping strategies such as prayer and reframing of difficult life circumstances, and the valuing of role performance to a greater extent than cognitive skills (Gallagher-Thompson et al., 2000). However, given recent findings suggesting that African Americans are at increased risk for $\mathrm{AD}$

TABLE 5. Analyses of covariance predicting scale scores

\begin{tabular}{|c|c|c|c|c|c|c|c|}
\hline \multirow[b]{2}{*}{ Predictor } & \multirow[b]{2}{*}{$d f$} & \multicolumn{2}{|c|}{$\begin{array}{c}\text { Factual } \\
\text { knowledge }\end{array}$} & \multicolumn{2}{|c|}{$\begin{array}{l}\text { Sources of } \\
\text { information }\end{array}$} & \multicolumn{2}{|c|}{$\begin{array}{l}\text { Perceived } \\
\text { threat of } \mathrm{AD}\end{array}$} \\
\hline & & Beta & $F$ value & Beta & $F$ value & Beta & $F$ value \\
\hline Race (white) & 1 & 2.00 & $59.85^{*}$ & 1.21 & $34.85^{*}$ & -3.58 & $36.58^{*}$ \\
\hline Age & 1 & -0.05 & $34.32 *$ & -0.01 & 1.58 & 0.04 & 2.87 \\
\hline Sex (female) & 1 & 0.95 & $10.21 *$ & 0.33 & 2.00 & -1.52 & $5.04 \dagger$ \\
\hline Education & 3 & & $12.48^{*}$ & & $8.59^{*}$ & & 1.21 \\
\hline High school or less & & -2.17 & & -1.56 & & -0.17 & \\
\hline Some college & & -1.44 & & -0.77 & & 0.94 & \\
\hline College graduate & & -0.97 & & -0.43 & & 1.11 & \\
\hline Graduate/professional & & - & & - & & - & \\
\hline Income $(\geq \$ 40,000)$ & 1 & 0.74 & $7.68^{*}$ & -0.08 & 0.15 & -0.99 & 2.68 \\
\hline Family history (yes) & 1 & 0.32 & 1.47 & 0.71 & $11.79 *$ & -3.64 & $37.59^{*}$ \\
\hline Caregiving history (yes) & 1 & 1.06 & $11.62 *$ & 0.99 & $15.81^{*}$ & -3.02 & $17.14 *$ \\
\hline
\end{tabular}

Note: Beta values indicate group differences in scale scores (e.g., Whites scored two points higher than blacks on Factual Knowledge scale). Lower scores indicate higher levels of perceived threat.

$* p<0.01$.

$\dagger p<0.05$. 
(Green et al., 2002), this group's relatively low level of perceived threat may be a cause for concern among dementia care providers.

Our findings must be interpreted with caution given the nonrepresentative nature of our sample. Although our study likely included a disproportionate number of health care workers, we unfortunately do not have data in this sample on racial group differences in occupation or study recruitment source. This precludes analyses using these potentially confounding variables. Also, our statistical controls for education did not take into account quality of education, which often differs across racial and ethnic groups. Furthermore, we acknowledge the challenge of accurately attributing differences in knowledge, attitudes, and beliefs about $\mathrm{AD}$ to group membership. When race is used as a grouping variable, it is not clear to what extent outcomes reported by African Americans should be attributed to their cultural distinctiveness or minority status, both of which may be confounded by socioeconomic status (Manuel, 2000). Finally, several of our illness belief items elicited a high proportion of "don't know" responses, especially among African Americans. Survey research experts have found that "don't know" replies cannot always be taken at face value, as respondents may have different reasons for selecting this answer (Beatty et al., 1998). Thus, this response pattern may have biased results on the factual knowledge and illness belief scales, and it may also indicate that some items were unclear or that the cultural validity of certain items was compromised. These study limitations should be addressed in future research in this area.

These preliminary results suggest a need for increased outreach and education efforts regarding $\mathrm{AD}$, particularly targeted to African Americans. Even among this relatively well-educated sample, in which health care workers were likely overrepresented, many participants demonstrated limited awareness of important facts about $\mathrm{AD}$; knowledge of possible treatments for the disorder seemed particularly limited. AD education efforts may draw upon lessons learned from research on cancer education for African Americans, in which studies have suggested that greater knowledge is associated with health promotion behaviors (Millon-Underwood and Sanders, 1990), and successful specialized prevention and education programs have been developed (Robinson et al., 1995). In addition, innovative outreach strategies such as the Michigan Interactive Health Kiosk Project (Connell et al., in press) demonstrate how information about $\mathrm{AD}$ can be disseminated widely to the general public, in this case through information "channels" in interactive electronic kiosks located at public places (e.g., churches, shopping malls, hospitals).
Additional research with more representative samples and more fully validated measures will be necessary to further explore and detail racial and ethnic differences in $\mathrm{AD}$ illness representations. Qualitative research may also be helpful in providing richer elaboration of cultural differences in perceptions of Alzheimer disease (Hinton and Levkoff, 1999) and in suggesting how these distinctions are likely to influence health behavior and decisionmaking. Such research will be crucial given the rising prevalence of $\mathrm{AD}$, the emergence of new, complex interventions for the disorder, and the important role of illness perceptions in shaping health decisions and behaviors (Petrie and Weinman, 1997).

Acknowledgments. The authors thank Dr. Jennifer Manly, Dr. Nancy Emerson Lombardo, and Dr. Giselle Corbie-Smith for their helpful comments on an earlier version of this manuscript.

\section{REFERENCES}

Alzheimer's Association. African Americans and Alzheimer's Disease: The Silent Epidemic. Chicago: Alzheimer's Association, 2002.

Ballard EL, Nash F, Raiford K, et al. Recruitment of black elderly for clinical research studies of dementia: the CERAD experience. Gerontologist 1993;33:561-65.

Barroso J, McMillan S, Casey L, et al. Comparison between AfricanAmerican and white women in their beliefs about breast cancer and their health locus of control. Cancer Nurs 2000;23:268-76.

Beatty P, Herrmann D, Puskar C, et al. "Don't know" responses in surveys: is what I know what you want to know and do I want you to know it? Memory 1998:6:407-26.

Becker MH. The health belief model and personal health behavior. Health Educ Monogr 1974;2:324-473.

Connell CM, Gibson GD. Racial, ethnic, and cultural differences in dementia caregiving: review and analysis. Gerontologist 1997;37: 355-64.

Connell CM, Shaw BA, Holmes SB, et al. Caregivers' attitudes toward their family members' participation in Alzheimer disease research: implications of recruitment and retention. Alzheimer Dis Assoc Disord 2001;15:137-45.

Connell CM, Shaw BA, Derry HA, et al. Development of an Alzheimer's disease channel for the Michigan Interactive Health Kiosk Project. J Health Commun In press.

Froehlich TE, Bogardus ST, Inouye SK. Dementia and race: are there differences between African Americans and Caucasians? J Am Geriatr Soc 2001;49:477-84.

Gallagher-Thompson D, Arean P, Coon D, et al. Development and implementation of intervention strategies for culturally diverse caregiving populations. In: Schulz R, ed. Handbook on Dementia Caregiving: Evidence-Based Interventions for Family Caregivers. New York: Springer, 2000:151-85.

Gauthier MA, Clarke WP. Gaining and sustaining minority participation in longitudinal research projects. Alzheimer Dis Assoc Disord 1999;13(suppl 1):29-33.

Green RC, Clarke VC, Thompson NJ, et al. Early detection of Alzheimer disease: methods, markers, and misgivings. Alzheimer Dis Assoc Disord 1997;11(suppl 5):1-5.

Green RC, Cupples LA, Go R, et al. Risk of dementia among white and African American relatives of patients with Alzheimer disease. JAMA 2002;287:329-36.

Haley WE, Roth DL, Coleton MI, et al. Appraisal, coping, and social support as mediators of well-being in black and white family care- 
givers of patients with Alzheimer's disease. J Consult Clin Psychol 1996;64:121-9.

Hargrave R. Strategies for working with African American caregivers of dementia patients. Paper presented at the annual meeting of the American Association for Geriatric Psychiatry, San Francisco, February 2001.

Hinton WL, Levkoff S. Constructing Alzheimer's: narratives of lost identities, confusion and loneliness in old age. Cult Med Psychiatry 1999;23:453-75.

Janevic MR, Connell CM. Racial, ethnic, and cultural differences in the dementia caregiving experience: recent findings. Gerontologist 2001;41:334-47.

Kumanyika S, Savage DD, Ramirez AG, et al. Beliefs about high blood pressure prevention in a survey of blacks and Hispanics. Am J Prev Med 1989;5:21-6.

Lawton MP, Rajagopal D, Brody E, et al. The dynamics of caregiving for a demented elder among black and white families. J Gerontol 1992;47(suppl):156-64.

Lazarus RS, Folkman S. Stress, Appraisal, and Coping. New York: Springer, 1984.

Leventhal H, Benyamini Y, Brownlee S, et al. Illness representations: theoretical foundations. In: Petrie KJ, Weinman JA, eds. Perceptions of Health and Illness. Amsterdam: Harwood, 1997:19-46.

Manly JJ, Jacobs D, Mayeux R. Alzheimer's disease among different ethnic and racial groups. In: Terry RD, Katzman R, Bick KL, et al., eds. Alzheimer's Disease, 2nd ed. Philadelphia: Lippincott Williams \& Wilkins, 1999:117-31.

Manuel RC. The conceptualization and measurement of race: confusion and beyond. Afr Am Res Perspect 2000;7-17.

Michielutte R, Diseker RA. Racial differences in knowledge of cancer: a pilot study. Soc Sci Med 1982;16:245-52.

Millon-Underwood S, Sanders E. Factors contributing to health promotion behaviors among African-American men. Oncol Nurs Forum 1990;17:707-12.

Petrie KJ, Weinman JA, eds. Perceptions of Health and Illness. Amsterdam: Harwood, 1997.

Roberts JS. Anticipating response to predictive genetic testing for Alzheimer's disease. Gerontologist 2000;40:43-52.

Roberts JS, Connell CM. Illness representations among first-degree relatives of people with Alzheimer disease. Alzheimer Dis Assoc Disord 2000;14:129-36.

Robinson KD, Kimmel EA, Yasko JM. Reaching out to the African American community through innovative strategies. Oncol Nurs Forum 1995;22:1383-91.

Welsh KA, Ballard E, Nash F, et al. Issues affecting minority participation in research studies of Alzheimer disease. Alzheimer Dis Assoc Disord 1994;8(suppl 4):38-48. 